Dublin Institute of Technology

ARROW@DIT

2006-01-01

\title{
The Involvement of Calcium and MAP Kinase Signaling Pathways in the Production of Radiation- Induced Bystander Effects
}

Fiona Lyng

Dublin Institute of Technology, Fiona.lyng@dit.ie

Paula Maguire

Dublin Institute of Technology

B. McClean

St. Luke's Hospital, Dublin

C. Seymour

St. Luke's Hospital, Dublin

Carmel Mothersill

Dublin Institute of Technology

Follow this and additional works at: http://arrow.dit.ie/radart

Part of the Pharmacology, Toxicology and Environmental Health Commons

\section{Recommended Citation}

Lyng, F. et al. (2006) The Involvement of Calcium and MAP Kinase Signaling Pathways in the Production of Radiation-Induced Bystander Effects. Radiation Research, Vol. 165 no. 4, pp.400-409.

This Article is brought to you for free and open access by the Radiation and Environmental Science Centre at ARROW@DIT. It has been accepted for inclusion in Articles by an authorized administrator of ARROW@DIT. For more information, please contact yvonne.desmond@dit.ie,

arrow.admin@dit.ie.

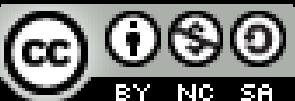




\title{
The Involvement of Calcium and MAP Kinase Signaling Pathways in the Production of Radiation-Induced Bystander Effects
}

\author{
F. M. Lyng, ${ }^{a, 1}$ P. Maguire, ${ }^{a}$ B. McClean,${ }^{b}$ C. Seymour ${ }^{b, 2}$ and C. Mothersill ${ }^{a, 2}$ \\ ${ }^{a}$ Radiation and Environmental Science Centre, Focas Institute, Dublin Institute of Technology, Dublin 8, Ireland; and b St. Luke's Hospital, \\ Rathgar, Dublin 6, Ireland
}

Lyng, F. M., Maguire, P., McClean, B., Seymour, C. and Mothersill, C. The Involvement of Calcium and MAP Kinase Signaling Pathways in the Production of Radiation-Induced Bystander Effects. Radiat. Res. 165, 000-000 (2006).

Much evidence now exists regarding radiation-induced bystander effects, but the mechanisms involved in the transduction of the signal are still unclear. The mitogen-activated protein kinase (MAPK) pathways have been linked to growth factor-mediated regulation of cellular events such as proliferation, senescence, differentiation and apoptosis. Activation of multiple MAPK pathways such as the ERK, JNK and p38 pathways have been shown to occur after exposure of cells to radiation and a variety of other toxic stresses. Previous studies have shown oxidative stress and calcium signaling to be important in radiation-induced bystander effects. The aim of the present study was to investigate MAPK signaling pathways in bystander cells exposed to irradiated cell conditioned medium (ICCM) and the role of oxidative metabolism and calcium signaling in the induction of bystander responses. Human keratinocytes (HPV-G cell line) were irradiated (0.005-5 Gy) using a cobalt-60 teletherapy unit. The medium was harvested $1 \mathrm{~h}$ postirradiation and transferred to recipient HPV-G cells. Phosphorylated forms of p38, JNK and ERK were studied by immunofluorescence $30 \mathrm{~min}-24 \mathrm{~h}$ after exposure to ICCM. Inhibitors of the ERK pathway (PD98059 and U0126), the JNK pathway (SP600125), and the p38 pathway (SB203580) were used to investigate whether bystander-induced cell death could be blocked. Cells were also incubated with ICCM in the presence of superoxide dismutase, catalase, EGTA, verapamil, nifedipine and thapsigargin to investigate whether bystander effects could be inhibited because of the known effects on calcium homeostasis. Activated forms of JNK and ERK proteins were observed after exposure to ICCM. Inhibition of the ERK pathway appeared to increase bystander-induced apoptosis, while inhibition of the JNK pathway appeared to decrease apoptosis. In addition, reactive oxygen species, such as superoxide and hydrogen peroxide, and calcium signaling were found to be important modulators of bystander responses. Further investigations of these signaling pathways may aid in the identification of novel therapeutic targets. 2006 by Radiation Research Society

\section{INTRODUCTION}

Much experimental evidence now challenges the central radiobiological paradigm that the biological effects of radiation occur as a direct consequence of energy deposition in DNA. Recent research has shown that low doses of ionizing radiation can cause a bystander effect, where an irradiated cell communicates with nonirradiated cells through secreted factors and/or gap junctional intercellular communication and the nonirradiated cells exhibit responses similar to those of irradiated cells [see reviews in refs. (14)]. While there is clear evidence for the existence of these bystander effects, an understanding of the mechanisms is only beginning to emerge.

Bystander responses include sister chromatid exchanges (5), micronucleus formation $(6,7)$, apoptosis (7-9), damage-inducible stress responses $(10,11)$, gene mutation $(12$, 13), chromosomal instability (14), transformation (15), reduction in clonogenic survival (16), and delayed cell death (17). Increased proliferation has also been reported $(18,19)$ as well as a protective adaptive response $(20,21)^{3}$ in which bystander cells that are treated subsequently are more radioresistant than cells not exposed to bystander signals.

The nature of the bystander signal remains unknown, although the properties are becoming clearer. Data are suggestive of a small protein molecule $(22,23)$, but it is also possible that long-lived radicals are produced (24). These molecules could all be involved and could interact to provide a progression from relatively short-lived radicals to more long-lived molecular species. A role for reactive oxygen species has been reported by many investigators $(8$, $9,22,25-30$ ). It is possible that generation of ROS may lead to the formation of bystander factors that generate ROS themselves, leading to a self-sustaining system responsible for long-lasting effects (31).

\footnotetext{
${ }^{1}$ Address for correspondence: Radiation and Environmental Science Centre, Dublin Institute of Technology, Kevin St., Dublin 8, Ireland; e-mail: fiona.lyng@dit.ie.

${ }^{2}$ Present address: Medical Physics an Applied Radiation Sciences, McMaster University, Hamilton, Ontario, Canada.

${ }^{3}$ P. Maguire, C. Seymour, C. Mothersill and F. M. Lyng, An adaptive response following exposure to medium from cells irradiated to low doses of cobalt 60 gamma rays. Manuscript submitted for publication.
} 
LYNG ET AL.

Multiple new signal transduction pathways have been discovered in the last 15 years. Many belong to the MAPK (mitogen-activated protein kinase) superfamily. These pathways are linked to growth factor-mediated regulation of diverse cellular events such as proliferation, senescence, differentiation and apoptosis (32).

Exposure of cells to ionizing radiation and other toxic stresses induces simultaneous compensatory activation of multiple MAPK pathways. These signals play critical roles in controlling cell survival after radiation exposure (32). Up-regulation of proteins in the MAPK pathway has been shown to occur in bystander cells (30). Activation of ERK, JNK and p38 in human fibroblasts was reported after exposure to low mean doses of $\alpha$ particles, and this activation was attenuated by antioxidants, superoxide dismutase (SOD) and catalase.

Calcium is an important signaling molecule. Changes in intracellular calcium modulate cell functions such as secretion, enzyme activation and cell cycle regulation and can lead to apoptosis $(33,34)$. Increased $\left[\mathrm{Ca}^{2+}\right]_{\mathrm{i}}$ has been shown to cause mitochondrial ROS formation (35). Lyng et al. (8, 9) have reported calcium fluxes, induction of ROS, and loss of mitochondrial membrane potential in cells exposed to medium from irradiated cells. A recent study demonstrated that irradiated $\mathrm{C} 57 \mathrm{BL} / 6$ mice but not $\mathrm{CBA} / \mathrm{Ca}$ mice produce bystander signals that induce calcium fluxes, loss of mitochondrial potential, and apoptosis in reporter HPV-G keratinocytes (36), indicating in vivo induction of bystander signals that are strongly influenced by genetic factors.

The aim of the present study was to investigate signaling pathways underlying radiation-induced bystander effects. Activation of MAPK pathways and the involvement of these pathways in bystander cell death were investigated. The role of both calcium signaling and ROS was also examined.

\section{MATERIALS AND METHODS}

\section{Cell Culture}

Human papilloma virus-immortalized keratinocytes (HPV-G), obtained as a kind gift from Dr. J. DiPaolo, NIH, Bethesda, MD (37), were cultured in Dulbecco's MEM:F12 medium (1:1) containing 7\% fetal calf serum, $1 \%$ penicillin-streptomycin solution (1000 IU), $25 \mathrm{mM}$ Hepes buffer, and $1 \mu \mathrm{g} / \mathrm{ml}$ hydrocortisone (all from Gibco Biocult Ltd., Irvine, Scotland) and were maintained in an incubator at $37^{\circ} \mathrm{C}$ in an atmosphere of $5 \%$ $\mathrm{CO}_{2}$ in air. Subculture was routinely performed using a 1:1 solution of $0.25 \%$ trypsin and $1 \mathrm{mM}$ versene at $37^{\circ} \mathrm{C}$.

\section{Irradiation}

Culture flasks $\left(25-\mathrm{cm}^{2}, 40-\mathrm{ml}\right.$ flasks, Nunc, Denmark) containing approximately $2 \times 10^{5}$ cells were irradiated at room temperature using a cobalt-60 teletherapy unit delivering approximately $1.8 \mathrm{~Gy} / \mathrm{min}$ during the period of these experiments. The source-to-sample distance was 80 $\mathrm{cm}$ and the field size was $30 \times 30 \mathrm{~cm}$. Control flasks were sham-irradiated. Cells were returned to the incubator immediately after irradiation.

\section{Generation of Irradiated Cell Conditioned Medium (ICCM)}

Medium from irradiated and unirradiated cells was poured off donor flasks $1 \mathrm{~h}$ after irradiation and filtered through a $0.22-\mu \mathrm{m}$ filter to ensure that no cells could still be present in the transferred medium (16). The medium was then divided into aliquots in $1-\mathrm{ml}$ volumes, stored at $-80^{\circ} \mathrm{C}$, and thawed only once when required for experiments. Recipient cells were plated onto glass cover slips (approximately $1 \times 10^{5}$ cells), grown to approximately $80 \%$ confluence, and exposed to ICCM as detailed below.

\section{Immunofluorescence}

An immunofluorescence method was used to visualize ERK, JNK and p38 antibodies. Cells were fixed in freshly prepared $4 \%$ paraformaldehyde at $30 \mathrm{~min}$ and $24 \mathrm{~h}$ after exposure to ICCM. After fixation for $1 \mathrm{~h}$, the cells were transferred to PBS and assayed immediately. Cells were permeabilized with cold $\left(-20^{\circ} \mathrm{C}\right)$ methanol, washed in PBS, and incubated in blocking buffer (1\% BSA, 5\% goat serum in PBS). Cells were then incubated with Anti Active antibodies to ERK, JNK and p38 (Promega, UK) overnight at $4^{\circ} \mathrm{C}$. After washing with PBS, cells were incubated with goat anti-rabbit FITC conjugate for 90 min followed by washing with PBS. Positive controls were HPV-G cells exposed to $0.5 \mathrm{~m} M$ sorbitol. Negative controls were cultures to which all reagents apart from the primary antibody were added. Positive and negative controls were included with every immunofluorescence run to correct for variability.

\section{Ratiometric Measurement of Calcium}

Intracellular calcium levels were determined relative to control levels using two visible-wavelength calcium-sensitive dyes, Fluo 3 and Fura Red (Molecular Probes, Leiden). Fluo 3 exhibits an increase in green fluorescence upon binding to calcium, whereas Fura Red exhibits a decrease in red fluorescence upon binding to calcium. The ratio Fluo 3/Fura Red is a good indicator of intracellular calcium levels (38). Cultures were washed twice with a buffer containing $130 \mathrm{~m} M \mathrm{NaCl}, 5 \mathrm{~m} M \mathrm{KCl}, 1 \mathrm{~m} M$ $\mathrm{Na}_{2} \mathrm{HPO}_{4}, 1 \mathrm{mM} \mathrm{CaCl}$, and $1 \mathrm{mM} \mathrm{MgCl}$ ( $\mathrm{pH}$ 7.4). Cells were loaded with the calcium-sensitive dyes by incubation with $3 \mu M$ Fluo 3 and 3 $\mu M$ Fura Red AM esters for $1 \mathrm{~h}$ in the buffer at $37^{\circ} \mathrm{C}$. Subsequently, the cultures were washed three times with buffer. Fluo 3 and Fura Red were excited at $488 \mathrm{~nm}$, and fluorescence emissions at $525 \mathrm{~nm}$ and $660 \mathrm{~nm}$ were recorded simultaneously using a Zeiss LSM 510 confocal microscope. Ratio images and time series data for the Fluo 3/Fura Red fluorescence intensities were recorded every $2 \mathrm{~s}$. Medium was added after 60 $\mathrm{s}$ when a stable baseline had been established. All measurements were performed at room temperature. The calcium ionophore A23187 (100 $\mathrm{n} M$ ) was used a positive control to exclude experimental artifacts.

The intracellular calcium concentration was calculated using the fluorescence intensity of Fluo 3 according to the equation

$$
\left[\mathrm{Ca}^{2+}\right]=K d\left[\frac{f / f_{o}}{9-(f / f o)}\right],
$$

where the value 9 is the dynamic range of Fluo 3. The dynamic range of an indicator is a measure of how much the fluorescence intensity changes upon binding of $\mathrm{Ca}^{2+} . K_{d}$ is the apparent $\mathrm{Ca}^{2+}$-binding affinity of Fluo 3 determined in situ $\left(K_{d}=810 \mathrm{nM}\right)$ and flfo is the relative change in Fluo 3 intensity (39).

\section{Measurement of Mitochondrial Membrane Potential}

Mitochondrial membrane potential was determined using rhodamine 123, a green fluorescent dye that accumulates in active mitochondria with high membrane potential (40). Cultures were washed twice with a buffer containing $130 \mathrm{~m} M \mathrm{NaCl}, 5 \mathrm{~m} M \mathrm{KCl}, 1 \mathrm{~m} M \mathrm{Na}_{2} \mathrm{HPO}_{4}, 1 \mathrm{~m} M \mathrm{CaCl}_{2}, 1$ $\mathrm{mM} \mathrm{MgCl}$, and $25 \mathrm{~m} M$ Hepes (pH 7.4). Cells were loaded with $5 \mu M$ Rhodamine 123 for $30 \mathrm{~min}$ in the buffer at $37^{\circ} \mathrm{C}$. Then the cultures were washed three times with buffer. Rhodamine 123 was excited at $488 \mathrm{~nm}$, and fluorescence emission at $525 \mathrm{~nm}$ was recorded using a Zeiss LSM 

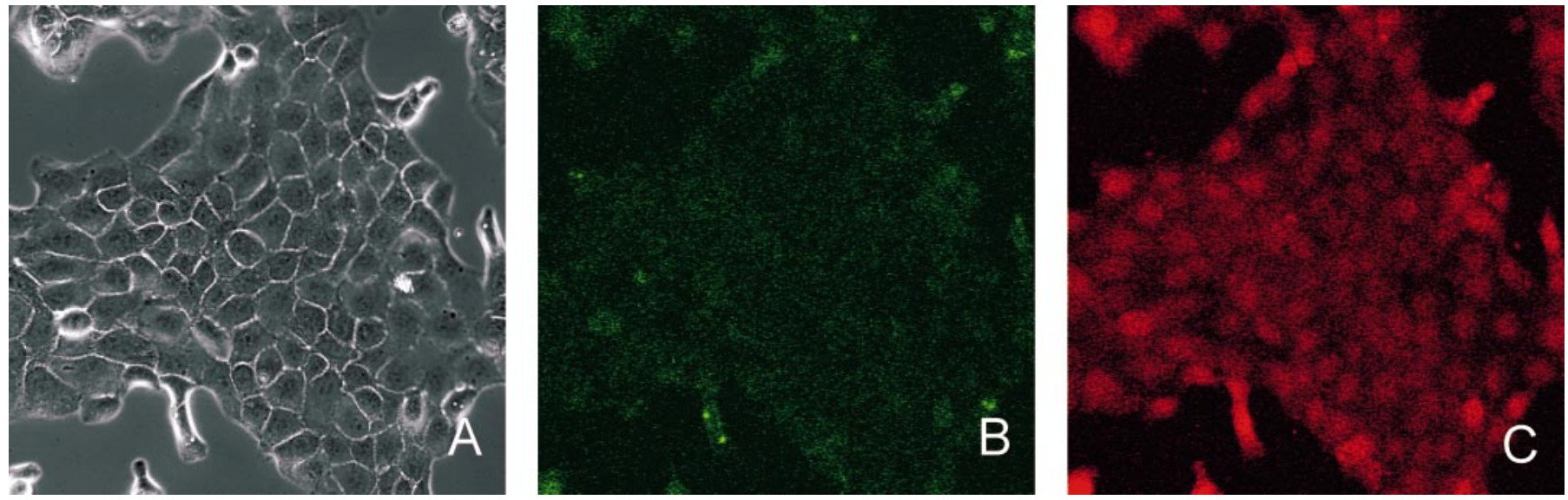

FIG. 1. Phase-contrast (panel A) and fluorescence images of Fluo 3 (panel B) and Fura Red (panel C) showing uniform dye loading and no compartmentalization after incubation at $37^{\circ} \mathrm{C}$ for $1 \mathrm{~h}$. The fluorescence intensity of Fura Red is higher than Fluo 3 , indicating low basal calcium levels.

META confocal laser scanning microscope. The mean fluorescence intensity (or mean gray value) was determined using Zeiss LSM software. Pretreatment of cells with $100 \mathrm{n} M$ valinomycin $\left(\mathrm{K}^{+}\right.$ionophore) for 20 min at $37^{\circ} \mathrm{C}$ before loading with $5 \mu M$ Rhodamine 123 for $30 \mathrm{~min}$ at $37^{\circ} \mathrm{C}$ was used a positive control to confirm that a reduction in fluorescence of Rhodamine 123 was due to a drop in mitochondrial membrane potential (41).

\section{Clonogenic Assay}

HPV-G cells were removed from the flask using $0.25 \% \mathrm{w} / \mathrm{v}$ trypsin $/ 1$ $\mathrm{m} M$ versene solution (1:1). When the cells had detached they were resuspended in medium, and an aliquot was counted using a Coulter counter model $\mathrm{Z}_{2}$ set at a threshold calibrated for the cell line using a hemocytometer. Three hundred cells were plated for the reporter assay to determine survival. The cells were plated $6 \mathrm{~h}$ before they were needed. Each flask received $4 \mathrm{ml}$ of ICCM harvested from the donor cultures and was incubated in a humidified $37^{\circ} \mathrm{C}$ incubator in an atmosphere of $5 \% \mathrm{CO}_{2}$ in air until macroscopic colonies had formed (approximately 7-9 days).

\section{Measurement of Apoptosis}

Apoptotic cells were scored $24 \mathrm{~h}$ after exposure to ICCM in five random fields containing approximately 100 cells each on in each of three replicate cover slips per treatment group. A cell was scored as apoptotic when it had a shrunken, dense morphology and a fragmented nucleus (42).

\section{Inhibitors of MAPK Pathways}

Cultures were exposed to ICCM in the presence or absence of inhibitors of MAPK pathways, and cell survival or apoptosis levels were measured. The MEK inhibitors U0126 and PD98059, were used at a final concentration of $20 \mu M$. The JNK inhibitor SP600125 was used at a final concentration of $10 \mu M$, and the p38 inhibitor SB203580 was used at a final concentration of $10 \mu M(43)$.

\section{Inhibitors of Calcium Influx and ROS}

Cultures were preincubated with inhibitors for $15 \mathrm{~min}$ and exposed to ICCM in the presence of the inhibitor as described for each of the assays. To inhibit ROS, cultures were exposed to ICCM in the presence or absence of superoxide dismutase (SOD) at a final concentration of $100 \mu \mathrm{g} /$ $\mathrm{ml}$ and catalase at a final concentration of $20 \mu \mathrm{g} / \mathrm{ml}$. For some experiments, solutions of SOD or catalase were placed in a boiling water bath for $2 \mathrm{~h}$ to inactivate the enzymes. The inactive enzymes were resuspended in solution before adding to the ICCM.

Cultures were exposed to ICCM in the presence or absence of EGTA at a final concentration of $5 \mathrm{mM}$ to chelate extracellular calcium, verapamil at a final concentration of $10 \mu M$, and nifedipine at a final concentration of $5 \mu M$ to block voltage-dependent calcium channels (44). An ER-associated calcium ATPase inhibitor, thapsigargin, at a final concentration of $150 \mathrm{n} M$ was used to deplete intracellular calcium stores in the presence of $5 \mathrm{~m} M$ EGTA (45).

\section{Statistical Analysis}

The data are expressed as the percentage means \pm standard errors of the means for each of three separate experiments.

\section{RESULTS}

\section{The Increase in Intracellular Calcium Results Mainly from Activation of a Calcium Influx Pathway}

Increases in intracellular calcium were measured using the calcium-sensitive dyes Fluo 3 and Fura Red. Uniform dye loading with no compartmentalization was observed after incubation of the cells for $1 \mathrm{~h}$ at $37^{\circ} \mathrm{C}$ (Fig. 1).

ICCM induced a rapid increase in calcium as measured by the Fluo 3/Fura Red ratio (Fig. 2). Figure 2 shows the reciprocal changes in each calcium-sensitive dye, Fluo 3 and Fura Red, for calcium ionophore A23187, a positive control and ICCM. By converting the relative change in fluorescence to $\left[\mathrm{Ca}^{2+}\right]$ as described in the Materials and Methods section, basal $\left[\mathrm{Ca}^{2+}\right]$ was determined to be 106.2 $\pm 2.2 \mathrm{nM}(n=12)$. The addition of the calcium ionophore A23187 induced a rapid transient increase in intracellular calcium to $342.3 \pm 9.7 \mathrm{n} M$ (Table 1). Carbachol induced a similar increase in intracellular calcium to $297.6 \pm 8.3$ $\mathrm{n} M$ (Table 1). The 0.5-Gy ICCM was found to increase $\left[\mathrm{Ca}^{2+}\right]$ to $283.8 \pm 5.7 \mathrm{n} M$ (Table 2), whereas the 0-Gy ICCM did not increase $\left[\mathrm{Ca}^{2+}\right]$ significantly $(108.4 \pm 1.7$ $\mathrm{n} M$, Table 2).

Chelation of extracellular calcium by EGTA or blockade 
LYNG ET AL
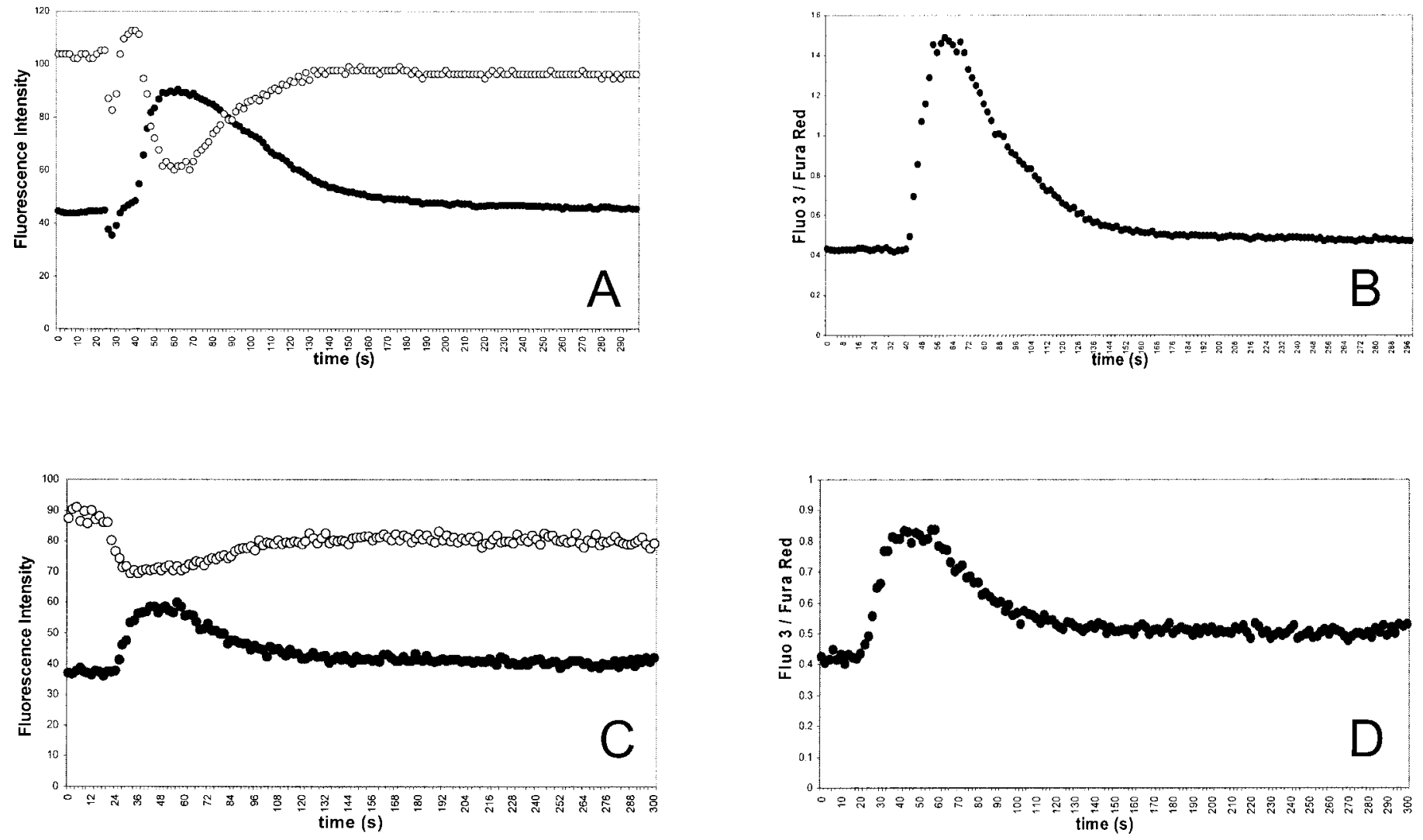

FIG. 2. Panel A: Fluorescence intensity of the calcium-sensitive dyes Fluo $3(\mathbf{)})$ and Fura Red $(\bigcirc)$ in response to addition of $100 \mathrm{n} M$ calcium ionophore A23187 and (panel B) the resulting ratiometric plot of Fluo 3/Fura Red. Panel C: Fluorescence intensity of Fluo 3 and Fura Red in response to addition of 0.5-Gy ICCM and (panel D) the resulting ratiometric plot of Fluo 3/Fura Red. Fluo 3 increases in intensity when bound to calcium whereas Fura Red decreases in intensity, and the ratio is a good indicator of calcium levels. The data shown are representative of at least nine similar plots.

of voltage-dependent calcium channels abolished the ICCM-induced calcium fluxes (Table 2). Two different classes of voltage-dependent calcium channel blockers were used, a dihydropyridine (nifedipine) and a phenylalkylamine (verapamil), and no significant difference was found between the two classes of blocker (Table 2). Control experiments confirmed that verapamil and nifedipine effectively blocked calcium channels in the HPV-G cells since no calcium influx was observed with carbachol after pretreatment with either inhibitor (Table 1). Depletion of intracellular calcium stores by thapsigargin attenuated but did not completely block the ICCM-induced calcium fluxes (Table 2). Control experiments showed that thapsigargin induced calcium release from intracellular stores when extracellular calcium levels were chelated with EGTA (Table 1).

\section{Influx of Calcium Plays an Important Role in Bystander Cell Death}

Clonogenic assays were carried out using ICCM in the presence and absence of EGTA and verapamil. No colonies formed in the flasks incubated with these agents (data not

TABLE 1

Basal and Peak $\left[\mathrm{Ca}^{2+}\right]$ after Exposure of HPV-G Cells to Calcium Ionophore A23187

$(100 \mathrm{n} M)$, Thapsigargin $(150 \mathrm{n} M)$ or Carbachol $(10 \mathrm{~m} M)$ and after Pretreatment with Calcium Channel Blockers Verapamil $(10 \mathrm{~m} M)$ or Nifedipine $(5 \mathrm{mM})$ before Addition of Carbachol (10 mM)

\begin{tabular}{llcc}
\hline & \multicolumn{1}{c}{ Function } & Basal $\left[\mathrm{Ca}^{2+}\right]$ & Peak $\left[\mathrm{Ca}^{2+}\right]$ \\
\hline Ionophore A23187 & Calcium ionophore & $107.5 \pm 1.0$ & $342.3 \pm 9.7^{*}$ \\
Thapsigargin & Depletes intracellular calcium stores & $104.8 \pm 1.1$ & $204.9 \pm 7.5^{*}$ \\
Carbachol & Stimulation of calcium influx & $103.8 \pm 0.5$ & $297.6 \pm 8.3^{*}$ \\
Verapamil + carbachol & Voltage-dependent $\mathrm{Ca}^{2+}$ channel blocker & $93.5 \pm 2.6$ & $103.6 \pm 1.2$ \\
Nifedipine + carbachol & Voltage-dependent $\mathrm{Ca}^{2+}$ channel blocker & $98.8 \pm 0.9$ & $105.9 \pm 1.6$ \\
\hline
\end{tabular}

Notes. Values are means $\pm \mathrm{SEM}, n=3$. $* P<0.002$. 
CALCIUM AND MAP KINASE SIGNALING PATHWAYS IN RADIATION-INDUCED BYSTANDER EFFECTS

TABLE 2

Peak $\left[\mathrm{Ca}^{2+}\right]$ in Cultures Exposed to 0-Gy ICCM or 0.5-Gy ICCM in the Presence of Inhibitors of Calcium and ROS

\begin{tabular}{llrc}
\hline & \multicolumn{1}{c}{ Function } & 0-Gy ICCM & 0.5-Gy ICCM \\
\hline No inhibitor & \multicolumn{1}{c}{-} & $108.4 \pm 1.7 \mathrm{n} M$ & $283.8 \pm 5.7 \mathrm{n} M^{* * *}$ \\
EGTA & Chelation of calcium & $94.7 \pm 2.6 \mathrm{n} M$ & $96.5 \pm 1.1 \mathrm{n} M$ \\
Verapamil & Voltage-dependent $\mathrm{Ca}^{2+}$ channel blocker & $93.7 \pm 1.6 \mathrm{n} M$ & $92.6 \pm 3.7 \mathrm{n} M$ \\
Nifedipine & Voltage-dependent $\mathrm{Ca}^{2+}$ channel blocker & $93.5 \pm 3.8 \mathrm{n} M$ & $96.1 \pm 1.0 \mathrm{n} M$ \\
Thapsigargin & Depletes intracellular calcium stores & $95.4 \pm 0.9 \mathrm{n} M$ & $171.9 \pm 3.7 \mathrm{n} M^{*}$ \\
SOD & Inhibitor of superoxide & $107.8 \pm 0.5 \mathrm{n} M$ & $108.7 \pm 1.7 \mathrm{n} M$ \\
Catalase & Inhibitor of hydrogen peroxide & $108.5 \pm 1.1 \mathrm{n} M$ & $109.7 \pm 1.6 \mathrm{n} M$ \\
\hline
\end{tabular}

Notes. Values are means \pm SEM, $n=3 . * P<0.01, * * P<0.002$.

shown), presumably because of the importance of calcium in cellular function. Levels of apoptosis were measured 24 $\mathrm{h}$ after incubation as an alternative end point. Significant levels of apoptosis were observed in HPV-G cells exposed to ICCM (Fig. 3). Cells preincubated with EGTA or verapamil and exposed to ICCM in the presence of EGTA or verapamil showed no significant increase in apoptosis (Fig. $3)$. In addition, cells preincubated with EGTA or verapamil and exposed to ICCM in the presence of EGTA or verapamil showed no change in mitochondrial membrane potential compared to the controls (Table 3). No significant toxicity of the EGTA and verapamil was found in the cells exposed to 0-Gy ICCM in the presence of these inhibitors using apoptosis and mitochondrial membrane potential as end points (Fig. 3, Table 3).
MAPK Pathways are Activated and Play a Role in Cell Survival and Cell Death Responses

ERK and JNK were significantly activated in cells exposed to 0.5-Gy ICCM (Figs. 4, 5), whereas p38 was not significantly activated (Fig. 5). There was no significant difference in the levels of activation at $30 \mathrm{~min}$ or $24 \mathrm{~h}$ (Fig. $5)$.

Clonogenic assays were carried out using ICCM in the presence and absence of MAPK inhibitors. Again, no colonies formed in the flasks incubated with these agents (data not shown). Levels of apoptosis were measured $24 \mathrm{~h}$ after incubation as an alternative end point. There was a significant increase in the number of apoptotic cells in HPV-G cells exposed to 0.5-Gy ICCM in the presence of inhibitors

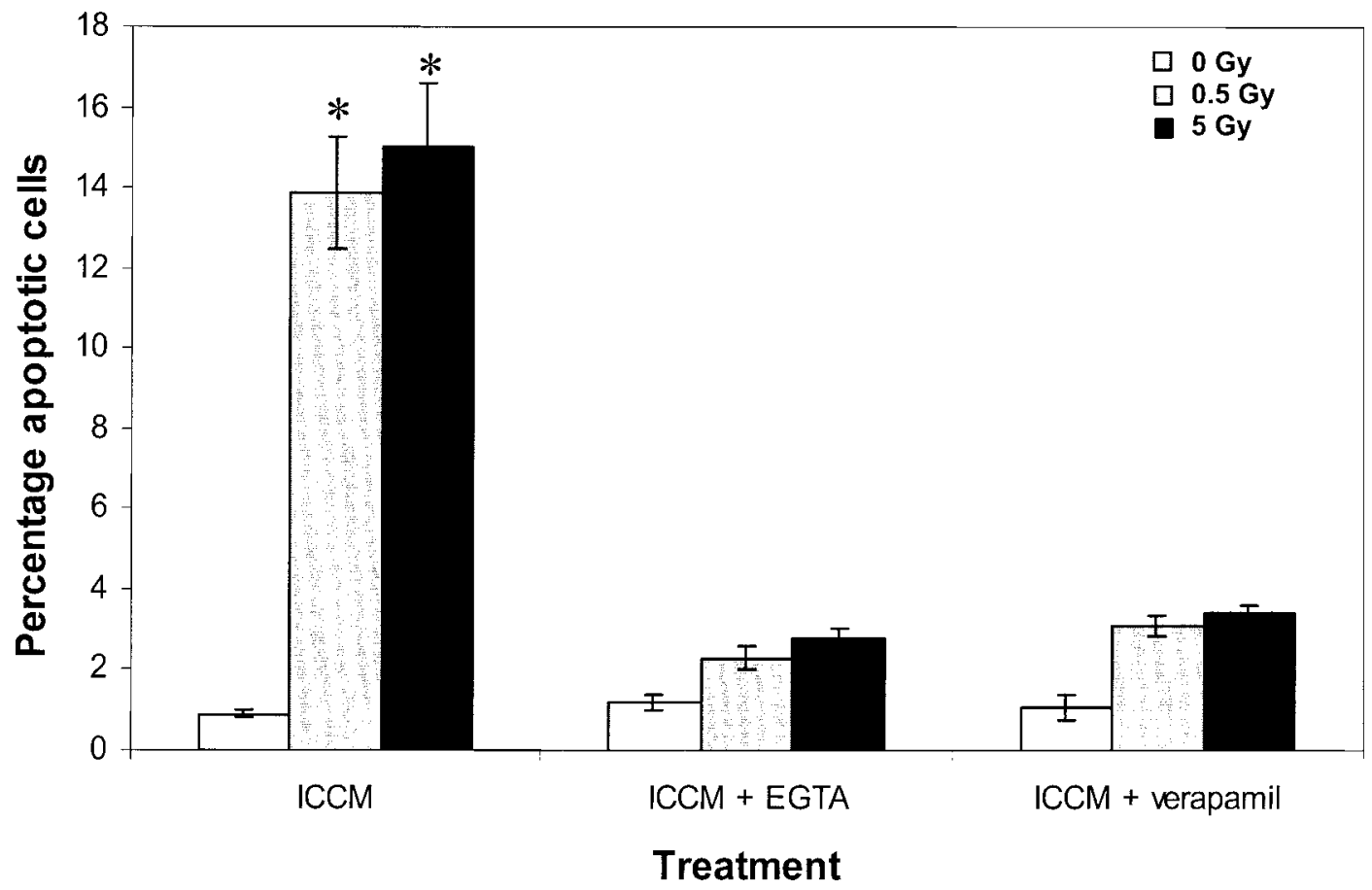

FIG. 3. Percentage apoptotic cells in cultures exposed to 0-Gy ICCM, 0.5-Gy ICCM or 5-Gy ICCM in the presence of inhibitors of calcium influx, EGTA $(5 \mathrm{mM})$ and verapamil $(10 \mu M)$. All values are means $\pm \mathrm{SEM}, n=3$. $* P<$ 0.001 . 
LYNG ET AL.

TABLE 3

Percentage Fluorescence in Cultures Exposed to 0-Gy ICCM or 0.5-Gy ICCM in the Presence of Inhibitors of Calcium and ROS

\begin{tabular}{llcl}
\hline & \multicolumn{1}{c}{ Function } & 0 -Gy ICCM & 0.5 -Gy ICCM \\
\hline No inhibitor & \multicolumn{1}{c}{-} & $100.0 \pm 10.3$ & $43.2 \pm 3.4^{*}$ \\
EGTA & Chelation of calcium & $106.9 \pm 7.7$ & $93.3 \pm 5.9$ \\
Verapamil & Voltage-dependent $\mathrm{Ca}^{2+}$ channel blocker & $103.8 \pm 10.8$ & $96.3 \pm 11.9$ \\
SOD & Inhibitor of superoxide & $113.1 \pm 6.7$ & $86.4 \pm 8.6$ \\
Catalase & Inhibitor of hydrogen peroxide & $99.4 \pm 7.2$ & $80.3 \pm 7.9$ \\
\hline
\end{tabular}

Notes. A decrease in fluorescence indicates a decrease in mitochondrial membrane potential. Values are means \pm SEM, $n=3 . * P<0.005$.

of the ERK pathway, U0126 and PD98059 (Table 4). There was a significant decrease in the number of apoptotic cells in HPV-G cells exposed to $0.5-$ Gy ICCM in the presence of an inhibitor of the JNK pathway, SP600125 (Table 4). No significant difference was observed in the number of apoptotic cells in HPV-G cells exposed to 0.5-Gy ICCM in the presence or absence of an inhibitor of the p38 pathway, SB230580 (Table 4). No significant toxicity from the MAPK inhibitors was found in the cells exposed to $0-G y$ ICCM in the presence of these inhibitors using apoptosis as an end point (Table 4).

\section{Reactive Oxygen Species Play an Important Role in Bystander Cell Death}

Reduced clonogenic survival was observed in HPV-G cells exposed to 0.5-Gy ICCM (Fig. 6). Cells preincubated with SOD or catalase and exposed to ICCM in the presence of SOD or catalase showed no change in clonogenic survival compared to the controls (Fig. 6). Mitochondrial membrane potential depolarization was observed in HPV$\mathrm{G}$ cells exposed to ICCM for $6 \mathrm{~h}$ as seen in the reduction in fluorescence of Rhodamine 123 (Table 3). Cells preincubated with SOD or catalase and exposed to ICCM in the presence of SOD or catalase showed no change in mitochondrial membrane potential compared to the controls (Table 3). Only active SOD or catalase was capable of preventing bystander-induced cell death (data not shown).

\section{DISCUSSION}

This study has shown that ERK and JNK, but not p38, pathways are activated in HPV-G cells exposed to ICCM. Inhibition of the ERK pathway appeared to increase bystander-induced apoptosis while inhibition of the JNK path-
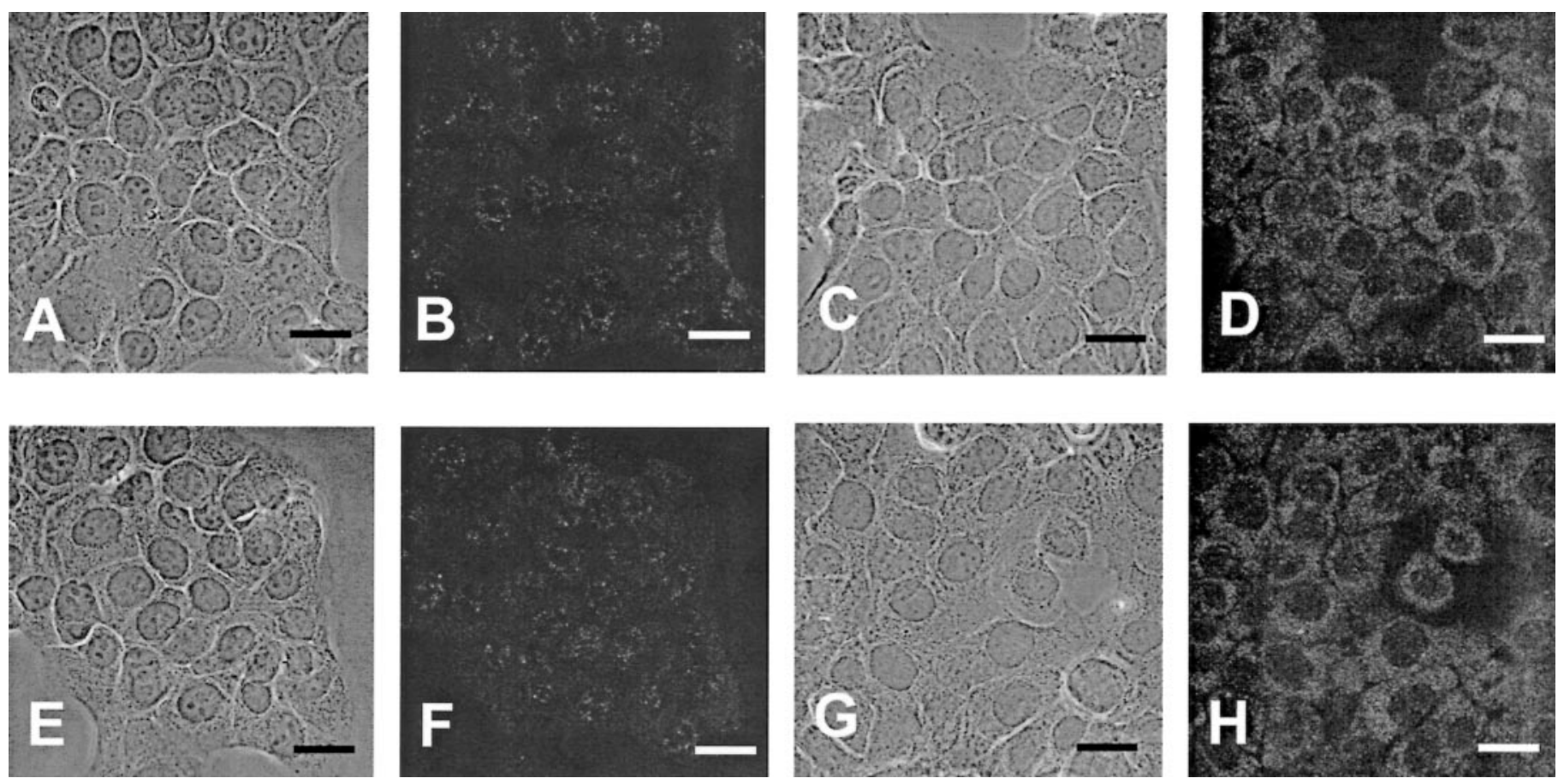

FIG. 4. Phase-contrast and fluorescence images of ERK protein levels in HPV-G cells exposed for 30 min to 0-Gy ICCM (panels A, B) and to 0.5Gy ICCM (panel C, D). Phase-contrast and fluorescence images of JNK protein levels in HPV-G cells exposed for 30 min to 0-Gy ICCM (panels E, F) and 0.5-Gy ICCM (panels G, H). Bar $=10 \mu \mathrm{m}$. 


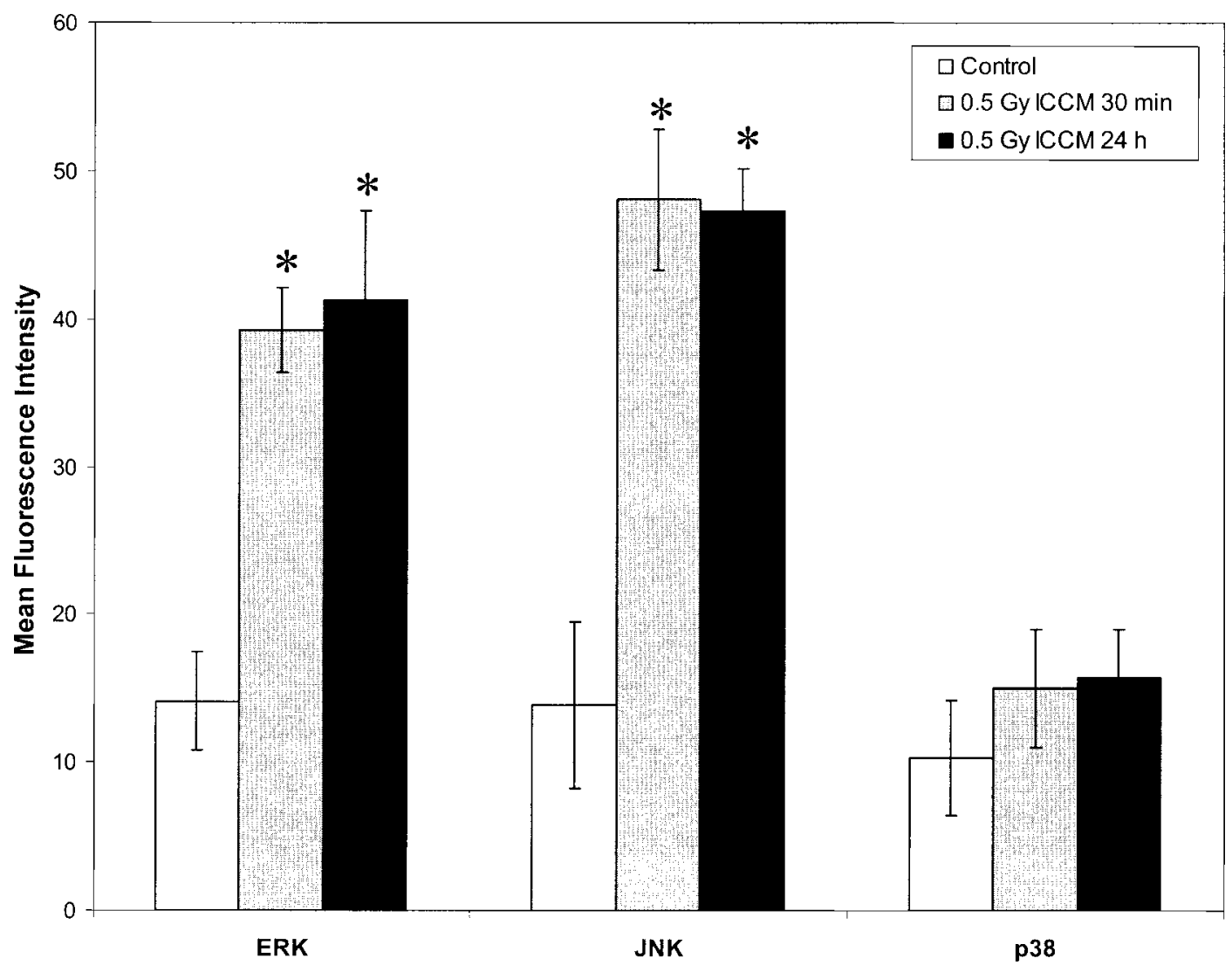

FIG. 5. Mean fluorescence intensity levels for ERK, JNK and p38 in cultures exposed to 0-Gy ICCM or 0.5-Gy ICCM for $30 \mathrm{~min}$ or $24 \mathrm{~h}$. All values are means $\pm \mathrm{SEM}, n=3$. $* P<0.001$.

way appeared to decrease apoptosis. ERK can be activated by many growth factors and mitogens, and JNK is known to be activated by UV and $\gamma$ radiation, cytotoxic drugs and reactive oxygen species (32). The ERK and JNK pathways appear to be in a dynamic balance, with the pro-survival ERK pathway acting to inhibit the pro-apoptosis JNK pathway (46). The p38 pathway has been shown to promote cell death as well as enhance cell growth and survival (47, 48). Various studies have reported no activation (49), weak activation (50) or strong activation (51) of p38 after exposure to ionizing radiation. Up-regulation of proteins in the MAPK pathway has been shown to occur in bystander cells (30). Activation of ERK, JNK and p38 was shown in human fibroblasts after exposure to low mean doses of $\alpha$ particles. The activation was attenuated by the antioxidants, SOD and catalase.

After exposure to ICCM, both intracellular and extracellular signals (apoptotic/survival/mitogenic) that determine whether a cell will live or die are altered. Mitochondria play a major role in this process. MAPK family proteins are also involved in determining proliferation or apoptosis in damaged cells (52). The JNK pathway may promote the proteolytic cleavage and translocation of BID (a pro-apoptosis $\mathrm{BH} 3$ protein of the BCL2 family) to the mitochondria before cytochrome c release and caspase activation (53). In addition, Tournier et al. (54) have shown that JNK activation may directly or indirectly affect the mitochondrial death signaling pathway including through release of cy-

TABLE 4

Percentage Apoptotic Cells in Cultures Exposed to 0-Gy ICCM or 0.5-Gy ICCM in the Presence of Inhibitors of the ERK, JNK and p38 Pathways

\begin{tabular}{llcc}
\hline & \multicolumn{1}{c}{ Function } & 0-Gy ICCM & $0.5-$-Gy ICCM \\
\hline No inhibitor & \multicolumn{1}{c}{-} & $1.6 \pm 0.2$ & $16.1 \pm 1.0$ \\
U0126 & MEK1 inhibitor & $1.7 \pm 0.3$ & $20.4 \pm 1.4^{*}$ \\
PD98059 & MEK1 and MEK2 inhibitor & $1.5 \pm 0.6$ & $19.1 \pm 1.8^{*}$ \\
SP600125 & JNK inhibitor & $1.2 \pm 0.4$ & $9.2 \pm 1.0^{* *}$ \\
SB203580 & p38 MAPK inhibitor & $1.5 \pm 0.1$ & $16.4 \pm 2.3$ \\
\hline
\end{tabular}

Notes. Values are means $\pm \mathrm{SEM}, n=3$. $* P<0.05, * * P<0.002$. 


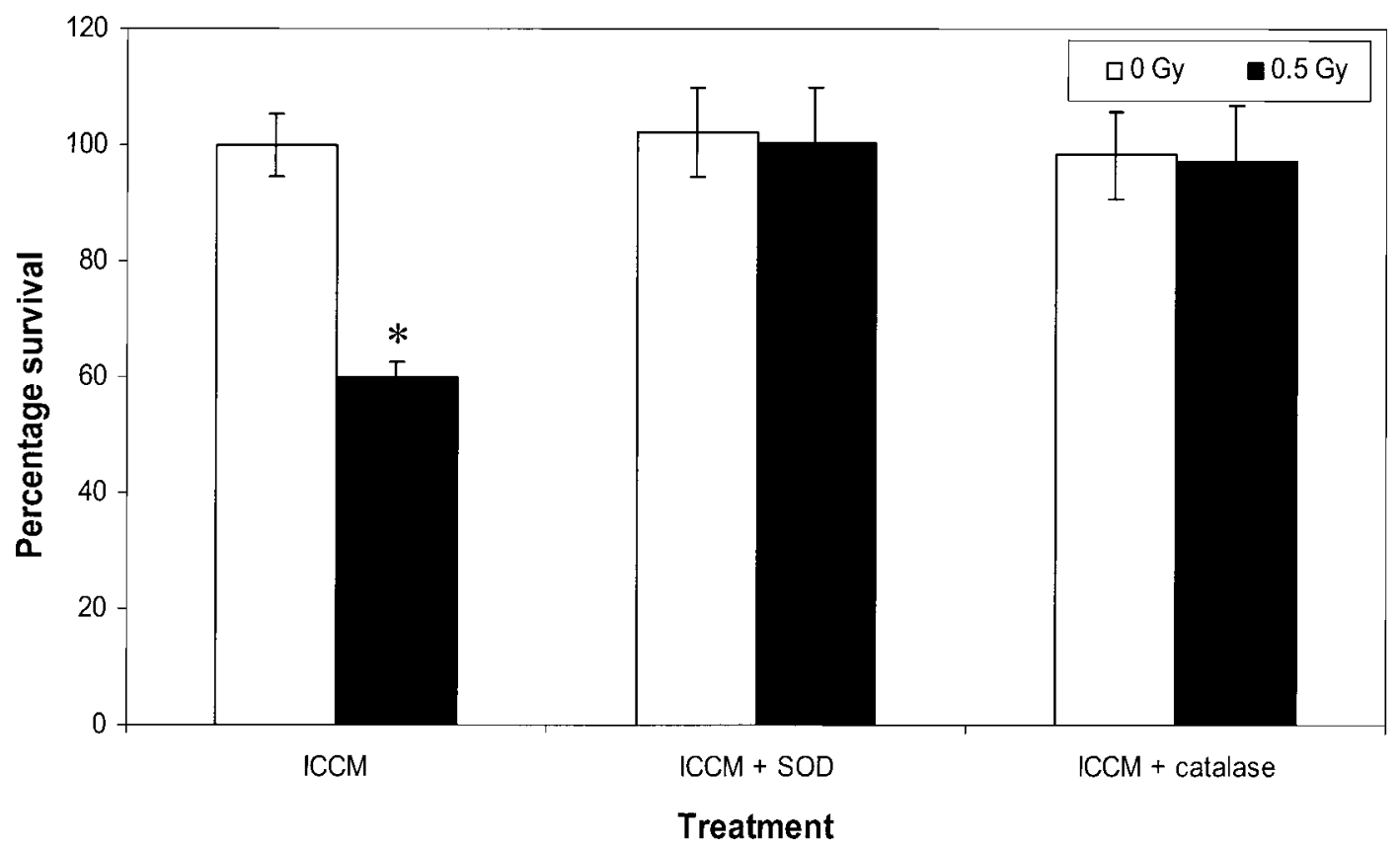

FIG. 6. Percentage survival in cultures exposed to 0 -Gy ICCM or $0.5-\mathrm{Gy}$ ICCM in the presence of inhibitors of reactive oxygen species, superoxide dismutase $(\mathrm{SOD})$ and catalase. All values are means $\pm \mathrm{SEM}, n=3$. $* P<$ 0.01 .

tochrome c and caspase activation. Recent studies in our own laboratory have shown that cytochrome $\mathrm{c}$ is released and caspase 3 is activated after mitochondrial membrane potential depolarization in HPV-G cells exposed to medium from irradiated cells. ${ }^{4}$ Ionizing radiation has been shown to activate the epidermal growth factor receptor (EGFR) (55), which in turn activates the MAPK cascade (56). In addition, ionizing radiation can induce transforming growth factor alpha (TGFA) release through ERK signaling (57). Interestingly, activation of EGFR-ERK signaling has been shown after transfer of medium from irradiated cells to unirradiated cells which could be eliminated by neutralizing antibody to TGFA (58). TGFA levels were also found to be increased in peripheral blood samples of prostate cancer patients after irradiation (58). Increases in transforming growth factor $\beta 1$ and IL8 have been shown previously in bystander cell supernatants $(18,59)$.

The present study has also shown the importance of oxidative metabolism in bystander responses. SOD and catalase were both shown to inhibit mitochondrial membrane potential depolarization and clonogenic survival. All cells generate ROS during the course of normal metabolism, but recent evidence indicates that many cytokines, hormones and growth factors can augment their immediate, transient or long-term expression $(60,61)$. ROS have been shown to be important for the activation of enzymes, transcription factors, differentiation and apoptosis $(62,63)$. Goldman et

${ }^{4}$ P. Maguire, C. Mothersill, N. Coen, C. Condron, B. McClean, C. Seymour and F. M. Lyng, Rapid cellular signalling and dose dependent cellular pathways induced in HPV-G cells exposed to medium from irradiated human keratinocytes. Manuscript submitted for publication. al. (64) showed that elevation of intracellular calcium is a prerequisite for ROS and phospholipase A2 activation in $\mathrm{HaCaT}$ cells exposed to different agonists and suggested that these processes contribute to the toxicity exerted by chronic elevation of calcium. A further study (65) on the effect of platelet-activating factor on ROS formation in HaCaT cells showed that $\mathrm{NAD}(\mathrm{P}) \mathrm{H}$ was a candidate for the ROS source and that the mitochondria were a potential site of formation. A recent study from our laboratory ${ }^{4}$ showed an increase in ROS concomitant with a transient depolarization of the mitochondrial membrane potential in HPV-G cells $30 \mathrm{~s}$ after exposure to ICCM. It is likely that the ICCM-induced elevation of intracellular calcium causes overload of calcium in the mitochondria, leading to a transient loss of membrane potential and production of ROS. This ROS production may then lead to activation of MAPK pathways and apoptosis. This is supported by data from Azzam et al. (30) that showed that activation of MAPK proteins was inhibited by SOD and catalase after $\alpha$-particle irradiation. In addition, it has been shown that formation of ROS leads to suppression of protein tyrosine phosphatase activity and enhanced protein tyrosine phosphorylation which culminates in the activation of the MAPK cascade in macrophages exposed to vanadate (66).

To summarize, in the present study, calcium influx from voltage-dependent calcium channels, and to a lesser extent calcium release from intracellular stores, was shown to be required for bystander-induced apoptosis. The data suggest that calcium release from the endoplasmic reticulum may be triggered by and dependent on ICCM-induced calcium influx through calcium channels. Thus the initial rise in 
CALCIUM AND MAP KINASE SIGNALING PATHWAYS IN RADIATION-INDUCED BYSTANDER EFFECTS

calcium levels may be further amplified by calcium release from intracellular stores. Calcium plays a central role in cellular signaling $(33,67)$. Its concentration in the cellular environment changes in response to a variety of signals. Like other signaling ions or molecules, generally an increase in its cytosolic concentration corresponds to an activation of a cellular function.

When calcium influx is inhibited by either EGTA or verapamil, the bystander response chain is blocked so no bystander-induced mitochondrial membrane potential depolarization or apoptosis occurs.

The data suggest that some long-lived signaling factors can cause apoptosis in unirradiated cells exposed to ICCM by triggering calcium fluxes and MAPK signaling pathways that induce ROS in the unirradiated cells.

\section{ACKNOWLEDGMENTS}

The authors acknowledge generous support from Science Foundation Ireland. We are very grateful to St Luke's Hospital, Dublin, for continued access to the cobalt 60 radiotherapy source.

Received: April 28, 2005; accepted: November 18, 2005

\section{REFERENCES}

1. C. Mothersill and C. B. Seymour, Radiation-induced bystander effects-implications for cancer. Nat. Rev. Cancer 4, 158-164 (2004).

2. S. A. Lorimore, P. J. Coates and E. G. Wright, Radiation-induced genomic instability and bystander effects: Inter-related nontargeted effects of exposure to ionizing radiation. Oncogene 22, 7058-7069 (2003).

3. J. B. Little, Genomic instability and bystander effects: a historical perspective. Oncogene 22, 6978-6987 (2003).

4. W. F. Morgan, Non-targeted and delayed effects of exposure to ionizing radiation: I. Radiation-induced genomic instability and bystander effects in vitro. Radiat. Res. 159, 567-580 (2003).

5. H. Nagasawa and J. B. Little, Induction of sister chromatid exchanges by extremely low doses of alpha particles. Cancer Res. 52, 63946396 (1992).

6. K. M. Prise, O. V. Belyakov, M. Folkard and B. D. Michael, Studies of bystander effects in human fibroblasts using a charged particle microbeam. Int. J. Radiat. Biol. 74, 793-798 (1998).

7. O. V. Belyakov, K. M. Prise, K. R. Trott and B. D. Michael, Delayed lethality, apoptosis and micronucleus formation in human fibroblasts irradiated with X-rays or alpha-particles. Int. J. Radiat. Biol. 75, 985993 (1999).

8. F. M. Lyng, C. B. Seymour and C. Mothersill, Production of a signal by irradiated cells which leads to a response in unirradiated cells characteristic of initiation of apoptosis. Br. J. Cancer 83, 1223-1230 (2000).

9. F. M. Lyng, C. B. Seymour and C. Mothersill, Initiation of apoptosis in cells exposed to medium from the progeny of irradiated cells: A possible mechanism for bystander-induced genomic instability? Radiat. Res. 157, 365-370 (2002).

10. A. W. Hickman, R. J. Jaramillo, J. F. Lechner and N. F. Johnson, Alpha-particle-induced p53 protein expression in a rat lung epithelial cell strain. Cancer Res. 54, 5797-5800 (1994).

11. E. I. Azzam, S. M. de Toledo, T. Gooding and J. B. Little, Intercellular communication is involved in the bystander regulation of gene expression in human cells exposed to very low fluences of alpha particles. Radiat. Res. 150, 497-504 (1998).

12. H. Nagasawa and J. B. Little, Unexpected sensitivity to the induction of mutations by very low doses of alpha-particle radiation: Evidence for a bystander effect. Radiat. Res. 152, 552-557 (1999).

13. H. Zhou, G. Randers-Pehrson, C. A. Waldren, D. Vannais, E. J. Hall and T. K. Hei, Induction of a bystander mutagenic effect of alpha particles in mammalian cells. Proc. Natl. Acad. Sci. USA 97, 20992104 (2000).

14. S. A. Lorimore, M. A. Kadhim, D. A. Pocock, D. Papworth, D. L. Stevens, D. T. Goodhead and E. G. Wright, Chromosomal instability in the descendants of unirradiated surviving cells after alpha-particle irradiation. Proc. Natl. Acad. Sci. USA 95, 5730-5733 (1998).

15. S. G. Sawant, G. Randers-Pehrson, C. R. Geard, D. J. Brenner and E. J. Hall, The bystander effect in radiation oncogenesis: I. Transformation in $\mathrm{C} 3 \mathrm{H} 10 \mathrm{~T}^{1} / 2$ cells in vitro can be initiated in the unirradiated neighbors of irradiated cells. Radiat. Res. 155, 397-401 (2001)

16. C. Mothersill and C. B. Seymour, Medium from irradiated human epithelial cells but not human fibroblasts reduces the clonogenic survival of unirradiated cells. Int. J. Radiat. Biol. 71, 421-427 (1997).

17. C. B. Seymour and C. Mothersill, Delayed expression of lethal mutations and genomic instability in the progeny of human epithelial cells that survived in a bystander-killing environment. Radiat. Oncol. Investig. 5, 106-110 (1997).

18. R. Iyer, B. E. Lehnert and R. Swensson, Factors underlying the cell growth-related bystander responses to alpha particles. Cancer Res. 60, 1290-1298 (2000).

19. C. Shao, M. Aoki and Y. Furusawa, Bystander effect on cell growth stimulation in neoplastic HSGc cells induced by heavy-ion irradiation. Radiat. Environ. Biophys. 42, 183-187 (2003).

20. R. Iyer and B. E. Lehnert, Alpha-particle-induced increases in the radioresistance of normal human bystander cells. Radiat. Res. 157, 3-7 (2002).

21. S. A. Mitchell, S. A. Marino, D. J. Brenner and E. J. Hall, Bystander effect and adaptive response in $\mathrm{C} 3 \mathrm{H} 10 \mathrm{~T}(1 / 2)$ cells. Int. J. Radiat Biol. 80, 465-472 (2004).

22. B. Lehnert, E. H. Goodwin and A. Deshpande, Extracellular factor(s) following exposure to alpha particles can cause sister chromatid exchanges in normal human cells. Cancer Res. 57, 2164-2171 (1997).

23. C. Mothersill and C. B. Seymour, Cell-cell contact during gamma irradiation is not required to induce a bystander effect in normal human keratinocytes: Evidence for release during irradiation of a signal controlling survival into the medium. Radiat. Res. 149, 256262 (1998).

24. E. I. Azzam, S. M. de Toledo and J. B. Little, Oxidative metabolism, gap junctions and the ionizing radiation-induced bystander effect. Oncogene 22, 7050-7057 (2003).

25. P. Naranayan, E. Goodwin and B. Lehnert, Alpha particles initiate biological production of superoxide anions and hydrogen peroxide in human cells. Cancer Res. 57, 2963-3971 (1997).

26. L. J. Wu, G. R. Randers-Pehrson, A. Xu, C. A. Waldren, C. R. Geard, Z. L. Yu and T. K. Hei, Targeted cytoplasmic irradiation with a particles induces mutations in mammalian cells. Proc. Natl. Acad. Sci. USA 96, 4959-4964 (1999).

27. C. Mothersill, T. D. Stamato, M. L. Perez, R. Mooney, R. Cummins and C. B. Seymour, Involvement of energy metabolism in the production of bystander effects by radiation. Br. J. Cancer 82, 17401746 (2000).

28. L. Huo, H. Nagasawa and J. B. Little, HPRT mutants induced in bystander cells by very low fluences of $\alpha$ particles result primarily from point mutations. Radiat. Res. 156, 521-525 (2001).

29. A. Bishayee, A. Z. Hill, D. Stein, D. V. Rao and R. W. Howell, Free radical-initiated and gap junction-mediated bystander effect due to nonuniform distribution of incorporated radioactivity in a three-dimensional tissue culture model. Radiat. Res. 155, 335-344 (2001).

30. E. I. Azzam, S. M. de Toledo, D. R. Spitz and J. B. Little, Oxidative metabolism modulates signal transduction and micronucleus formation in bystander cells from alpha-particle-irradiated normal human fibroblast cultures. Cancer Res. 62, 5437-5442 (2002).

31. I. Emerit, S. H. Khan and P. A. Cerutti, Treatment of lymphocyte 
LYNG ET AL.

cultures with a hypoxanthine-xanthine oxidase system induces the formation of transferable clastogenic material. J. Free Radic. Biol. Med. 1, 51-7 (1985).

32. P. Dent, A. Yacoub, P. B. Fisher, M. P. Hagan and S. Grant, MAPK pathways in radiation responses. Oncogene 22, 5885-5896 (2003).

33. D. E. Clapham, Intracellular calcium. Replenishing the stores. Nature 375, 634-635 (1995)

34. F. L. Bygrave and H. R. Roberts, Regulation of cellular calcium through signaling cross-talk involves an intricate interplay between the actions of receptors, G-proteins, and second messengers. FASEB J. 9, 1297-1303 (1995).

35. A. C. Rego and C. R. Oliveira, Mitochondrial dysfunction and reactive oxygen species in excitotoxicity and apoptosis: Implications for the pathogenesis of neurodegenerative diseases. Neurochem. Res. 28, 1563-1574 (2003).

36. C. Mothersill, F. Lyng, C. Seymour, P. Maguire, S. Lorimore and E. Wright, Genetic factors influencing bystander signaling in murine bladder epithelium after low-dose irradiation in vivo. Radiat. Res. 163, 391-399 (2005)

37. L. Pirisi, K. E. Creek, J. Doniger and J. DiPaolo, Continuous cell lines with altered growth and differentiation properties originate after transfection of human keratinocytes with human papillomavirus type 16 DNA. Carcinogenesis 9, 1573-1579 (1988).

38. P. Lipp and E. Niggli, Ratiometric confocal $\mathrm{Ca}^{2+}$-measurements with visible wavelength indicators in isolated cardiac myocytes. Cell Calcium 14, 359-372 (1993).

39. D. Thomas, S. C. Tovey, T. J. Collins, M. D. Bootman, M. J. Berridge and P. Lipp, A comparison of fluorescent $\mathrm{Ca}^{2+}$ indicator properties and their use in measuring elementary and global $\mathrm{Ca}^{2+}$ signals. Cell Calcium 28, 213-223 (2000).

40. C. Ferlini, S. Di Cesare, G. Rainaldi, W. Malorni, P. Samoggia, R. Biselli and A. Fattorossi, Flow cytometric analysis of the early phases of apoptosis by cellular and nuclear techniques. Cytometry 24, 106115 (1996).

41. A. Cossarizza, D. Ceccarelli and A. Masini, Functional heterogeneity of isolated mitochondrial population revealed by cytofluorimetric analysis at the single organelle level. Exp. Cell Res. 222, 84-94 (1996).

42. J. F. Kerr, C. M. Winterford and B. V. Harmon, Apoptosis. Its significance in cancer and cancer therapy. Cancer 73, 2013-2026 (1994).

43. K. Matsuda, T. Idezawa, X. J. You, N. H. Kothari, H. Fan and M. Korc, Multiple mitogenic pathways in pancreatic cancer cells are blocked by a truncated epidermal growth factor receptor. Cancer Res. 62, 5611-5617 (2002).

44. C. M. Doolan, S. B. Condliffe and B. J. Harvey, Rapid non-genomic activation of cytosolic cyclic AMP-dependent protein kinase activity and $\left[\mathrm{Ca}^{2+}\right]_{\mathrm{i}}$ by $17 \beta$-oestradiol in female rat distal colon. Br. J. Pharmacol. 129, 1375-1386 (2000).

45. M. Hoth and R. Penner, Depletion of intracellular calcium stores activates a calcium current in mast cells. Nature 355, 353-356 (1992).

46. J. A. Vrana, S. Grant and P. Dent, Inhibition of the MAPK pathway abrogates BCL2-mediated survival of leukemia cells after exposure to low-dose ionizing radiation. Radiat. Res. 151, 559-569 (1999).

47. N. Juretic, J. F. Santibanez, C. Hirtado and J. Martinez, ERK 1, 2 and p38 pathways are involved in the proliferative stimuli mediated by urokinase in osteoblastic SaOS-2 cell line. J. Cell Biochem. 83, 92-98 (2001).

48. G. Yosimichi, T. Nakanishi, T. Nishida, T. Hattori, T. Takano-Yamamoto and M. Tagigawa, CTGF/Hcs24 induces chondrocyte differentiation through a p38 mitogen-activated protein kinase (p38MAPK), and proliferation through a p44/42 MAPK/extracellular-signal regulated kinase (ERK). Eur. J. Biochem. 268, 6058-6065 (2001).

49. S. J. Kim, J. W. Ju, C. D. Oh, Y. M. Yoon, W. K. Song, J. H. Kim, Y. J. Yoo, O. S. Bang, S. S. Kang and J. S. Chun, ERK-1/2 and p38 kinase oppositely regulate nitric oxide-induced apoptosis of chondrocytes in association with p53, caspase-3, and differentiation status. J. Biol. Chem. 277, 1332-1339 (2002).
50. M. M. Taher, C. M. Hershey, J. D. Oakley and K. Valerie, Role of the p38 and MEK-1/2/p42/44 MAP kinase pathways in the differential activation of human immunodeficiency virus gene expression by ultraviolet and ionizing radiation. Photochem. Photobiol. 71, 455459 (2000).

51. Y. J. Lee, J. W. Soh, N. M. Dean, C. K. Cho, T. H. Kim, S. J. Lee and Y. S. Lee, Protein kinase $\mathrm{C} \Delta$ overexpression enhances radiation sensitivity via extracellular regulated protein kinase $1 / 2$ activation, abolishing the radiation-induced $\mathrm{G}_{2}-\mathrm{M}$ arrest. Cell Growth Differ. 13, 237-246 (2002).

52. T. Wada and J. M. Penninger, Mitogen-activated protein kinases in apoptosis regulation. Oncogene 23, 2838-2849 (2004).

53. M. A. Bae and B. J. Song, Critical role of c-Jun N-terminal protein kinase activation in troglitazone-induced apoptosis of human HepG2 hepatoma cells. Mol. Pharmacol. 63, 401-408 (2003).

54. C. Tournier, P. Hess, D. D. Yang, J. Xu, T. K. Turner, A. Nimnual, D. Bar-Sagi, S. N. Jones, R. A. Flavell and R. J. Davis, Requirement of JNK for stress-induced activation of the cytochrome c-mediated death pathway. Science 288, 870-874 (2000).

55. R. K. Schmidt-Ullrich, R. B. Mikkelsen, P. Dent, D. G. Todd, K. Valerie, B. D. Kavanaugh, J. N. Contessa, W. K. Rorrer and P. B. Chen, Radiation induced proliferation of the human A431 squamous carcinoma cells is dependent on EGFR tyrosine phosphorylation. Oncogene 15, 1191-1197 (1997).

56. P. Dent, D. B. Reardon, J. S. Park, G. Bowers, C. Logsdon, K. Valerie and R. K. Schmidt-Ullrich, Radiation induced release of transforming growth factor a activates the epidermal growth factor receptor and mitogen activated protein kinase pathway in carcinoma cells, leading to increased proliferation and protection from radiation induced cell death. Mol. Biol. Cell. 10, 2493-2506 (1999).

57. M. Hagan, L. Wang, J. R. Hanley, J. S. Park and P. Dent, Ionizing radiation-induced mitogen activated protein (MAP) kinase activation in DU145 prostate carcinoma cells: MAP kinase inhibition enhances radiation-induced cell killing and $\mathrm{G}_{2}-\mathrm{M}$ phase arrest. Radiat. Res. 153, 371-383 (2000).

58. M. Hagan, A. Yacoub and P. Dent, Ionizing radiation causes a dose dependent release of transforming growth factor a in vitro from irradiated xenografts and during palliative treatment of hormone refractory prostate carcinoma. Clin. Cancer Res. 10, 5724-5731 (2004).

59. P. K. Narayanan, K. E. LaRue, E. H. Goodwin and B. E. Lehnert, Alpha particles induce the production of interleukin- 8 by human cells. Radiat. Res. 152, 57-63 (1999).

60. Y. S. Bae, S. W. Kang, M. S. Seo, I. C. Baines, E. Tekle, P. B. Chock and S. G. Rhee, Epidermal growth factor (EGF)-induced generation of hydrogen peroxide. Role in EGF receptor-mediated tyrosine phosphorylation. J. Biol. Chem. 272, 217-221 (1997).

61. H. I. Krieger Brauer and $\mathrm{H}$. Kather, The stimulus-sensitive $\mathrm{H}_{2} \mathrm{O}_{2}-$ generating system present in human fat-cell plasma membranes is multireceptor-linked and under antagonistic control by hormones and cytokines. Biochem. J. 307, 543-548 (1995).

62. R. Goldman, E. Ferber and U. Zort, Reactive oxygen species are involved in the activation of cellular phospholipase A2. FEBS Lett. 309, 190-192 (1992).

63. N. S. Chandel, P. T. Schumacker and R. H. Arch, Reactive oxygen species are downstream products of TRAF-mediated signal transduction. J. Biol. Chem. 276, 42728-42736 (2001).

64. R. Goldman, S. Moshonov and U. Zor, Generation of reactive oxygen species in a human keratinocyte cell line: role of calcium. Arch. Biochem. Biophys. 350, 10-18 (1998).

65. R. Goldman, S. Moshonov and U. Zor, Calcium-dependent PAF-stimulated generation of reactive oxygen species in a human keratinocyte cell line. Biochim. Biophys. Acta 1438, 349-358 (1999).

66. R. Goldman, E. Ferber and U. Zor, Involvement of reactive oxygen species in phospholipase A2 activation: Inhibition of protein tyrosine phosphatases and activation of protein kinases. Adv. Exp. Med. Biol. 400, 25-30 (1997).

67. M. J. Berridge, P. Lippa and M. D. Bootman, The versatility and universality of calcium signalling. Natl. Rev. Mol. Cell Biol. 1, 11$21(2000)$. 